\title{
Weight loss in women with hyperemesis gravidarum admitted in a tertiary hospital \\ S Kabir ${ }^{1}$, MS Basher ${ }^{2}$, T Latif ${ }^{3}$, SMN Akhter ${ }^{4}$, L Nahar ${ }^{5}$, SA Shaon 6
}

\begin{abstract}
Background: Hyperemesis gravidarum is the most severe form of nausea and vomiting in pregnancy with poor pregnancy outcome. Hormonal, psychological, immunological, and infection with $H$. pylori contribute to the condition.

Objective: To estimate the weight loss in women with Hyperemesis gravidarum.

Methods: A descriptive, cross sectional study was carried out at antenatal ward, Mymensingh Medical College Hospital, Mymensingh for a period of twenty one months among purposively selected thirty-six patients with hyperemesis gravidarum admitted into the hospital.

Results: Highest number (16-44.4\%) of respondents were in age group 20 to 24 years with a mean of $23.8 \pm 4.5$ years. Majority 29 (80.6\%) of the women had education less than 12 years, whereas as many as 28 (77.8\%) women were housewives, and at least 14 (38.9\%) women had unplanned pregnancies. An overwhelming majority 29 (80.6\%) of women had their pregnancy duration of 8 to 12 weeks with a mean of $10.6 \pm 2.4$ weeks. Majority 20 (55.6\%) of women were pregnant for the first time, while 19 (52.8\%) women had duration of illness for 5 to 9 weeks. Mean difference in body weight was $3.9 \pm 2.0 \mathrm{Kg}$. The loss of weight ranged from 3 to 8 kilograms with a mean of $3.9 \pm 1.4 \mathrm{Kg}$. Loss of weight ranged from 5.0 to 16.7 percent with a mean $7.9 \pm 2.8$ percent. Out of 16 multigravid women, 7 (43.8\%) had history of similar condition in their previous pregnancies.
\end{abstract}

Conclusion: First trimester was time of manifestation of the condition. Patient with Hyperemesis gravidarum often presents with vomiting over 10 times a day with dehydration and remarkable loss of body weight.

Key words: Hyperemesis gravidarum, Weight loss, Pregnancy.

\section{Introduction}

Nausea and vomiting in pregnancy is a common health problem.1-3 Mild to moderate nausea and vomiting are common in early pregnancy and known as emesis gravidarum, while the most severe form is called Hyperemesis gravidarum. ${ }^{4}$ hyperemesis gravidarum affects 0.3 to 1.5 percent live births. Moreover, it is the most common indication of hospitalization during first trimester.5,6 Hyperemesis gravidarum can seriously affect health and well being of the pregnant women and her unborn foetus. ${ }^{4}$ Furthermore, it has deleterious effects like dehydration, metabolic acidosis due to starvation, metabolic alkalosis resulting from loss of hydrochloric acid, electroly teimbalance like hypokalaemia, and weight loss.1,2 Hyperemesis gravidarum cases with more than five percent weight loss coupled with long term under nourishment result in adverse pregnancy outcomes. 6,7,9 Increased level of human Chorionic Gonadotrophin (hCG), oestradiol and progesterone are possible contributing factors. 2,10 In addition, thyroxine, prolactin, leptin and adreno cortical hormones are also involved in the pathogenesis of Hyperemesis gravidarum. Besides hormones, psychogenic, dietary deficiency and allergic or immunological factors play role in the pathogenesis of hyperemesis gravidarum. ${ }^{2}$ Moreover, there is an association between

1. Shikha Kabir, Lecturer, Department of Community Medicine, Mymensingh Medical College, Mymensingh.

2. Md. Shahidul Basher, Professor, Dept. of Community Medicine, Mymensingh Medical College.

3. Tanzina Latif, Asstt. Prof, Obst and Gynaecology, Mymensingh Medical College.

4. SM Nahida Akhter, Asstt. Prof, Obst and Gynae, Mymensingh Medical College.

5. Lutfun Nahar, Sr. Consultant, Model Family Planning Clinic, Mymensingh Medical College Hospital

6. Simla Aftab Shaon, Jr. Consultant, Obst and Gynae, Mymensingh Medical College Hospital. 
infection with $H$. pylori and Hyperemesis gravidarum. Socio-economic status is an important risk factor for $\mathrm{H}$ pylori infection in pregnant women with hyperemesis gravidarum. ${ }^{11}$ During pregnancy, increased level of steroid hormones and Human Chorionic Gonadotrophin (hCG) favour activation of helicobacter pylori infection. ${ }^{1,5,8}$ Besides, altered humoral and cell mediated immunity contribute to the manifestation of a latent helicobacter pylori infection.1,5 Helicobacter pylori captures as well as utilizes iron for its survival, results in bleeding gastritis and interferes with iron absorption from the gut. Consequently, severe anaemia may complicate the pregnancy and childbirth in the form of antepartum haemorrhage, obstructed labour, postpartum haemorrhage and retained placenta. Over and above, undernutrition has been described in relation to hyperemesis gravidarum as a consequence of the disease, not as a cause. Loss of weight of mother with hyperemesis coupled with long term undernourishment result in adverse pregnancy outcomes like low birth weight, preterm delivery and congenital anomalies. ${ }^{12}$ The study was directed to estimate the weight loss in women with Hyperemesis gravidarum.

\section{Materials and Methods}

A descriptive cross sectional study was carried out at antenatal ward, department of Obstetrics and Gynaecology, Mymensingh Medical College Hospital for a period ranging from September 1, 2014 to May 31, 2016. Hyperemesis gravidarum patients with age range from 18 to 35 years with pregnancy duration of 6 to 17 weeks were included in the study. However, patients with thyroid diseases, multiple pregnancy, molar pregnancy, infections like UTI, hepatitis, meningitis, appendicitis, cholecystitis and pancreatitis, and gastrointestinal diseases like PUD and small bowel obstruction etc. were excluded from the study. During the study period total 56 patients got admitted into the aforementioned hospital. Of them, thirty-six women were purposively selected for the study following inclusion and exclusion criteria. Before pregnancy, they were quite all right, and food habits were usual for a Bangladeshi national. After obtaining informed written consent, data were collected through interview when the patient became stable enough, and recorded in pretested Case Record Form (CRF). Gestational age was determined using the first date of last menstrual period, and confirmed by ultrasonography. Prepregnancy body weight was recorded by the version of the respondents. However, in case of 8 women who did not know their prepregnancy weight were asked to assume the weight loss during current pregnancy. Then prepregnancy weight was estimated by addition of current pregnancy weight with assumed lost weight. Weight during pregnancy was measured by using mechanical bathroom scale, made by NIKAI, model no. 822, Tokyo, Japan. Before taking weight the scale was adjusted at zero. At the end of each interview and filling up of each Case Record Form (CRF), the same was cross checked for completeness, consistency, and discrepancy. Stool sample was tested for Helicobacter pylori Stool Antigen (HpSA) using HpSA enzyme linked immunosorbent assay (One Step H. pylori Ag Rapid test, OMC Healthcare (Pvt.) Ltd., Canada, 201213) according to manufacturer's instructions. Statistical analyses were performed using SPSS (Statistical Package for Social Sciences) version 20.0 for Windows (SPSS Inc, Chicago, III, USA).

\section{Results}

A descriptive, cross sectional study was carried out among 36 women to measure the weight loss in women with Hyperemesis gravidarum. Highest number (16-44.4\%) of respondents were in age group 20 to 24 years with a mean of $23.8 \pm 4.6$ years. As many as 32 (88.9\%) women were literate, whereas $28(77.8 \%)$ respondents were housewives. At least $22(61.1 \%)$ respondents had planned pregnancies, while 20 (55.6\%) women were primigravid. Mean pregnancy duration was $10.6 \pm 2.4$ weeks. Duration of illness in 19 (52.8\%) respondents was 5 to 9 weeks with mean $5.5 \pm 2.0$ weeks. Onset of manifestation for hyperemesis gravidarum in $23(63.9 \%)$ of women was between 5 to 9 weeks, while in $13(36.1 \%)$ women it was in first 4 weeks. Of 16 multigravid women, 7 (43.8\%) had history of similar condition. Majority 31 $(86.1 \%)$ of the women had average built, whereas 3 (8 3\%) were emaciated and 1 (2.8\%) each had below average and more than average built. Body Mass Index (BMI) of the respondents ranged from 15.2 to $25.3 \mathrm{Kg}$ with a mean of $20.8 \pm 2.0 \mathrm{Kg}$ per square metre. As many as 31 (86.1\%) women had normal BMI, while $4(11.1 \%)$ women were underweight and only $1(2.8 \%)$ was overweight (Fig. 1). 


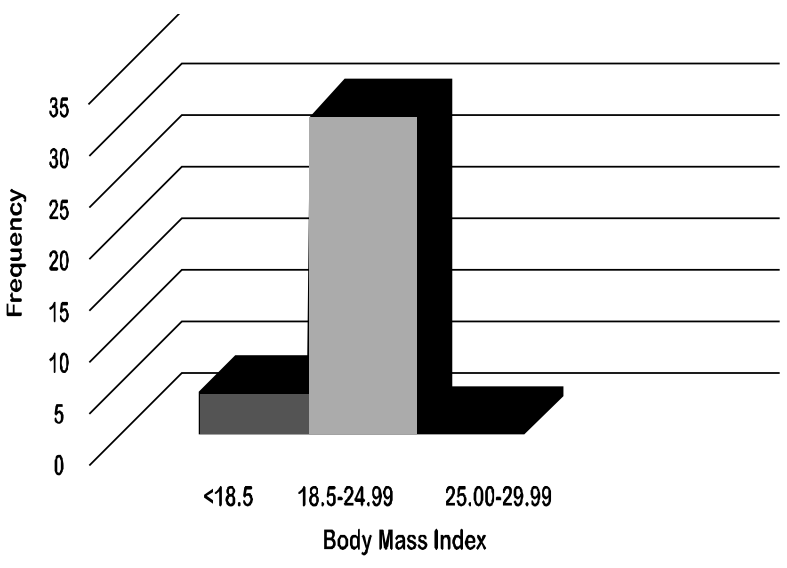

Fig-1. Histogram showing Body Mass Index of Women with Hyperemesis Gravidarum

Before pregnancy, majority $18 \quad$ (50.0\%) of respondents had body weight from 50 to 54 kilograms with mean $52.2 \pm 4.9$. Whereas during pregnancy, highest 16 (44.4\%) women had weight between 45 to 49 kilograms with mean $48.1 \pm 5.1$. Difference of body weight before pregnancy and during pregnancy ranged from 3 to 10 kilograms with high statistical significance $(\mathrm{p}<0.001)$ (Table-I).

\section{Table I}

Respondents by body weight status

\begin{tabular}{lcc}
\hline Weight in Kg & $\begin{array}{c}\text { Before } \\
\text { Pregnancy (\%) }\end{array}$ & $\begin{array}{c}\text { During } \\
\text { Pregnancy (\%) }\end{array}$ \\
\hline $35-39$ & 0 & $3(8.3)$ \\
$40-44$ & $1(2.8)$ & $1(2.8)$ \\
$45-49$ & $9(25.0)$ & $16(444)$ \\
$50-54$ & $18(50.0)$ & $13(36.1)$ \\
$55-59$ & $5(13.9)$ & $1(2.8)$ \\
$60-64$ & $2(5.5)$ & $2(5.6)$ \\
$65-69$ & $1(2.8)$ & 0 \\
Total & 36 & 36 \\
\hline Mean $\pm \mathrm{SD}$ & $52.2 \pm 4.9 \mathrm{Kg}$ & $48.1+5.1 \mathrm{Kg}$ \\
t35 =13.30; $\mathrm{P}<0.001$ &
\end{tabular}

The loss of weight ranged from 3 to 8 kilograms with mean $3.9+1.4$ (Table II). In majority 30 $(83.3 \%)$ of women, weight loss was between 5 to 10 percent, while in $5(13.9 \%)$ women it was between 10 to 15 percent and in $1(2.8 \%)$ woman it was between 15 to 20 percent with mean weight loss of $7.6 \pm 2.8$ (Table III).
Table II

Respondents by loss of weight during pregnancy

\begin{tabular}{lcc}
\hline Weight in Kg & Frequency & Percentage \\
\hline $0-4$ & 27 & 75.0 \\
$5-9$ & 9 & 25.0 \\
Total & 36 & 100.0 \\
\hline
\end{tabular}

Mean $(\mathrm{x})=3.9 \mathrm{Kg} ; \mathrm{SD}=1.4 \mathrm{Kg}$

Stool samples of 11 (30.6\%) women were positive for HpSA. Out of 11 women with stool specimen positive for $\mathrm{H}$. pylori infection, $2(18.2 \%)$ had no sign of dehydration, while $6(54.5 \%)$ had some sign of dehydration and $3(27.3 \%)$ had severe dehydration. While women with negative HpSA test result (25), as many as $7(18.0 \%)$ had no sign of dehydration, whereas $18(12.0 \%)$ had some dehydration. Statistical association between HpSA test result and dehydration status was just significant $(\mathrm{p}=0.05)$.

\section{Table III}

Respondents by loss of weight in body weight percentage

\begin{tabular}{lcc}
\hline $\begin{array}{l}\text { Weight loss in } \\
\text { Percentage of } \\
\text { body weight }\end{array}$ & Frequency & Percentage \\
\hline $5-10$ & 30 & 83.3 \\
$10-15$ & 5 & 13.9 \\
$15-20$ & 1 & 2.8 \\
Total & 36 & 100.0 \\
\hline
\end{tabular}

Mean $(\mathrm{x})=7.6 \% ; \mathrm{SD}=2.8 \%$

\section{Discussion}

It was observed that highest number 16 (41.4\%) of the respondents were in age group 20 to 24 years, while an overwhelming majority 29 (80.6\%) of the women had educational status below 12 years, and as many as 20 (55.6\%) women were pregnant for the first time. These findings are substantiated by observation made by Lee and Saha (2011) that nausea and vomiting in pregnancy is more common in younger women, primigravida and women with less than 12 years of education. ${ }^{14}$

Majority (29-80.6\%) of the women had their pregnancy duration between 8 to 12 weeks. Out of 16 multi gravid women, 7 (43.8\%) had history of similar condition in their previous pregnancies, while among 36 women, 9 (25.0\%) had family history of similar condition and a significant number 14 (18.9\%) of women had unplanned 
pregnancy. These findings are in line with the observation made by Dutta (2015) that hyperemesis gravidarum is mostly limited to the first trimester, more common in first pregnancy with a tendency to recur in subsequent pregnancies, runs in family and most common in unplanned pregnancies. ${ }^{2}$

In majority 23 (63.9\%) respondents, onset of hyperemesis gravidarum was between 5 to 9 weeks. As many as 21 (58.3\%) pregnant women had vomiting frequency of 10 to 12 times a day, and in cent per cent women loss of weight was five percent or more in comparison to their prepregnancy weight status. These findings are vindicated by the observation made by Carmella (2012) that hyperemesis gravidarum usually starts during the first 12 weeks of pregnancy, vomiting more than three times per day with dehydration and weight loss five percent of pre-pregnancy body weight. ${ }^{15}$

In $23(63.9 \%)$ women, manifestation of hyperemesis gravidarum started between 5 to 9 weeks of gestation. These findings are in agreement with the observation made by $\mathrm{Abd} \mathrm{Al}$ wahed et al. (2014) that nausea and vomiting in pregnancy usually starts between 4 to 9 gestational weeks, becomes maximum at 12 to 15 weeks. 1 Moreover, these are corroborated by the observation made by Carmella (2012) that hyperemesis gravidarum usually starts during the first 12 weeks of pregnancy. ${ }^{15}$ Out of thirty-six, 11 $(30.6 \%)$ stool samples were positive for H.pylori stool antigen. This is more or less consistent with the findings of case control study conducted by Bezircioglu et al. (2011) in Turkey with H.pylori infection rate of 22.2 percent among cases. ${ }^{5}$ Besides, it has more or less concordance with findings of prospective study carried out by Karadeniz et al. (2005) with 22.6 percent prevalence of $\mathrm{H}$. pylori infection among cases. ${ }^{16}$

Purposive sampling technique was used for the selection of the study units which hinders the generalization of the study findings. HpSA test is for qualitative detection of H.pylori in stool sample and does not indicate the quantity of the antigen. A negative result does not preclude the possibility of infection with $\mathrm{H}$. pylori. Intake of antibiotics and Proton Pump Inhibitors (PPI) might show the negative result despite infection with Helicobacter pylori.

\section{Conclusion}

First trimester is the period of onset of hyperemesis gravidarum. Patient with hyperemesis gravidarum often presents with vomiting more than ten times a day including dehydration and significant loss of body weight.

\section{References:}

1. AbdAlwahed AR, Elsaadany HM, Radwa, AM, Noureldin $\mathrm{M}$ and Kuma, RK. Role of Helicobacter Pylori Eradication in the Management of Hyperemesis gravidarum. Research Journal of Obstetrics and Gynaecology 2014; 7: 6-13.

2. Dutta DC. DC Dutta's Textbook of Obstetrics including Perinatology and Contraception, Eighth Edition, New Delhi 2015: pp. 180-306.

3. Niemeijer MN, Grooten U, Vos N, Bais JMJ, Van der Post JA., Mol BW, Roseboom TJ, Leeflang MMG and Painter RC. Diagnostic Markers for Hyperemesis Gravidarum: Systemic Review and Meta Analysis, American Journal of Obstetrics and Gynaecology 2014: 150.

4. G Rajakumari A, Sunthia M and Soli TK. First Trimester Hyperemesis Gravidarum: A Case Report, International Journal of Allied Medical Sciences and Clinical Research 2014 2: 491-493.

5. Bezircioglu 1, Elveren HB, Baloglu A and Bicer M. The Positivity of Helicobacter Stool Antigen in Patients with Hyperemesis Gravidarum, Journal of the Turkish German Gynaecological Association 2011; 12: 71-74.

6. Verberg MFG, Gillot DJ, Al Fardan N and Grudzinskas JG. Hyperemesis Gravidarum, a Literature Review, Human Reproduction Update 2005 8: 1-13.

7. Philip B. Hyperemesis Gravidarum: Literature Review, Wisconsin Medical Journal 2003; 102: 46-51.

8. Vikanes ASE, GrJibovski AM, Vangen S and Magnus P. Variations in Prevalence of Hyperemesis Gravidarum by Country of Birth: A Study of 900074 Pregnancies in Norway, 1967 2005, Scandinavian Journal of Public Health 2008; 36: 135-142.

9. Weyermann M, Rothenbache, D, Gayer L, Bode G and Adler $\mathrm{G}$ et al. Role of Helicobacter Pylori Infection in Iron Deficiency During Pregnancy, American Journal of Obstetrics and Gynaecolo 2005; 192: 548-553.

10. Chad KK and Daniel HS Gastrointestinal Disorders in Pregnancy. In Decherney, A.H., Nathan L, Laufer N and Roman AS. Current Diagnosis and Treatment of Obstetrics and Gynaecology, 11th Edition, North America 2013: pp.493-500.

11. Karaca C, Guler N, Yazar A, Camlica H, Demir K and Yildirim G. Is Lower Socioeconomic Status a Risk Factor for Helicobacter pylori Infection in Pregnant Women with Hyperemesis Gravidarum?, Turkish Journal of Gastroenterology 2004;15: 86-89.

12. Nashaat EH and Mansour GM. Helicobacter Pylori and Hyperemesis Gravidarum Continuous Study (2), Nature and Science 2010; 8: 22-26.

13. Anonymous. One Step H.PyloriAg Rapid Test Kit, OMC Healthcare (PVL) Ltd., Ref. Q02-05A-6, Canada, November, PN: J900013, 2012: 1-6.

14. Lee NM and Saha S. Nausea and Vomiting of Pregnancy, Gastroenterology Clinics of North America 2011; 40: 309.

15. Carmella. W. [Online] Hyperemesis Gravidarum: Causes, Symptoms and Diagnosis Retrieved from http://www.healthline.com/health/hyperemesis gravidarum Healthline, August 2012; 7: 6.

16. Karadeniz RS, Ozdegirmenci 0, Altay MM, Solaroglu A, Dilbaz S, Hizel N and Haberal A. Helicobacter pylori Seropositivity and Stool Antigen in Patients With Hyperemesis Gravidarum, Infectious Diseases in Obstetrics and Gynecology 2006: 1-3. 